\title{
Dynamic Characteristics of Rotating Stall in Mixed Flow Pump
}

\author{
Xiaojun Li, ${ }^{1}$ Shouqi Yuan, ${ }^{1}$ Zhongyong Pan, ${ }^{1}{ }^{Y i}$ Li, $^{2}$ and Wei Liu ${ }^{1}$ \\ ${ }^{1}$ Research Center of Fluid Machinery Engineering and Technology, Jiangsu University, Zhenjiang, Jiangsu 212013, China \\ ${ }^{2}$ School of Mechanical Engineering and Automation, Zhejiang Sci-Tech University, Hangzhou, Zhejiang 310018, China
}

Correspondence should be addressed to Xiaojun Li; lixiaojun530@163.com

Received 3 June 2013; Accepted 21 August 2013

Academic Editor: Bo Yu

Copyright (C) 2013 Xiaojun Li et al. This is an open access article distributed under the Creative Commons Attribution License, which permits unrestricted use, distribution, and reproduction in any medium, provided the original work is properly cited.

\begin{abstract}
Rotating stall, a phenomenon that causes flow instabilities and pressure hysteresis by propagating at some fraction of the impeller rotational speed, can occur in centrifugal impellers, mixed impellers, radial diffusers, or axial diffusers. Despite considerable efforts devoted to the study of rotating stall in pumps, the mechanics of this phenomenon are not sufficiently understood. The propagation mechanism and onset of rotating stall are not only affected by inlet flow but also by outlet flow as well as the pressure gradient in the flow passage. As such, the complexity of these concepts is not covered by the classical explanation. To bridge this research gap, the current study investigated prerotation generated at the upstream of the impeller, leakage flow at the tip clearance between the casing and the impeller, and strong reserve flow at the inlet of the diffuser. Understanding these areas will clarify the origin of the positive slope of the head-flow performance curve for a mixed flow pump. Nonuniform pressure distribution and adverse pressure gradient were also introduced to evaluate the onset and development of rotating stall within the diffuser.
\end{abstract}

\section{Introduction}

Gopalakrishnan pointed out that the three primary requirements of pump research and development can be broadly divided into three categories: hydraulic (with emphasis on improving the prediction of performance and improvement of impeller life), vibrations (with the aim of providing cost-effective capability for problem solving/avoidance), and pump design [1]. Flow instabilities and unsteadiness, flowinduced noise, and flow-induced vibration in pumps have been continuously studied for years [2-4]. Advanced diagnostics for pump performance and failure must be provided attention to analyze flow fields and their responses [5]. Various studies that focused on these issues have contributed to the development and production of pumps [2-7]. In the last two years, researchers have focused on an unsteady flow feature called rotating stall [8-11], which is one of the most important sources of unsteadiness at partial flow rates for pumps. Unsteadiness occurs when the pressure increase in the rotor which exhibits a positive slope. Predicting the dynamic characteristics of rotating stall and gaining detailed information on the head-flow performance curve of pumps are very important as vibration and noise increase at partial flow rates where the positive slope of a head-flow performance curve appears easily.

This study attempts to illustrate the relationship between pump characteristic instability and the rotating stall. Rotating stall is briefly summarized, including its causes, propagation mechanism, and onset, as well as the structure of the stall cell. A mixed flow pump with a positive slope in the head-flow performance curve is then investigated, and the relationship between the head-flow characteristic instability and design parameters is discussed in detail. The change in flow topology in the diffuser is related to the positive slope; reverse flow and adverse pressure gradient are thereby introduced to evaluate the onset and development of rotating stall within the diffuser.

\section{Review of Rotating Stall in Pumps}

The stable operating range of a pump is limited at the partload flow rate. With decreasing flow rate, the relative velocity of the incoming fluid in the impeller throat is decelerated, whereas the incidence angle at the impeller leading edge (LE), which is the difference between the incoming flow angle 


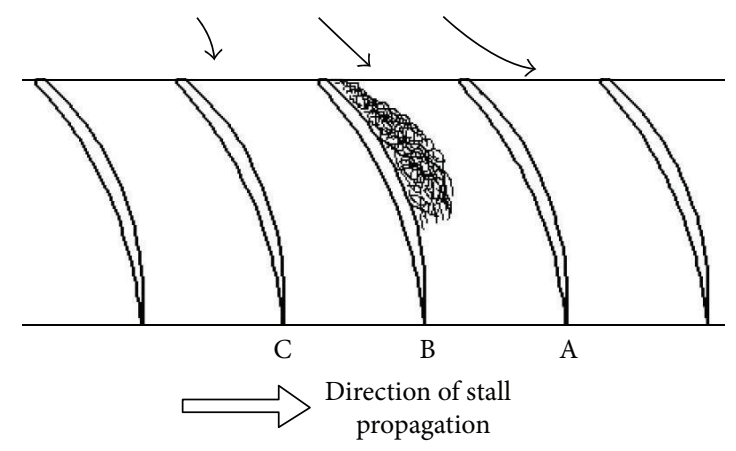

FIGURE 1: Rotating stall phenomenon in a diffuser.

and the blade angle, is accelerated. If the flow rate is further reduced, the flow would become unstable and would separate from the blade suction surface. A stall may occur and block the passage of the impeller. When a rotating stall occurs, one or more stall cells rotate around the axis and propagate at some fraction of the impeller's rotational speed; standing stall cells have been observed in the passage of the impeller in several cases [12].

The common method of explaining the onset and development of rotating stall in a diffuser is illustrated in Figure 1. In a row of blades operating at a high angle of incidence, if blade $B$ is stalled, a separate wake is generated that blocks the flow in the passage between blades B and A. The blockage in the passage will divert the flow away from blade B, thereby increasing the angle of incidence on blade $\mathrm{A}$ and reducing that on blade C. Thus, blade A would stall, whereas any stall on blade $\mathrm{C}$ would diminish. The stall will therefore propagate from left to right in the figure if conditions are suitable. This case is seen in the diffuser, whereas that in the rotating impeller is slightly different [11].

Although Emmons et al. presented a coherent explanation of propagating stall in compressors in 1955 [13], understanding of the mechanism of this phenomenon remains limited. Rotating stall is frequently observed and widely studied in compressors, and an important issue is predicting both the onset and consequence of a rotating stall. A useful criterion is that rotating stall occurs when the stall approaches the maximum in the total head rise and the flow coefficient decreases. This condition is, however, no more than a crude approximation, and Greitzer quoted a number of cases in which rotating stall occurs while the slope of the performance curve is still negative [14]. A more sophisticated criterion widely used is from Leiblein and involves the diffusion factor, Df, defined as

$$
\mathrm{Df}=1-\frac{w_{2}}{w_{1}}+\frac{v_{\theta 2}-v_{\theta 1}}{2 s w_{1}},
$$

where $s$ is solidity. Rotating stall may begin when Df is increased to a value of about 0.6. Rotating stall has not, however, been reported in axial pumps with a small number of blades, perhaps because Df will not approach 0.6 in typical axial pumps or inducers with a small number of blades.

As for pumps, several studies of rotating stall have been made in which rotating stall causes the positive slope of

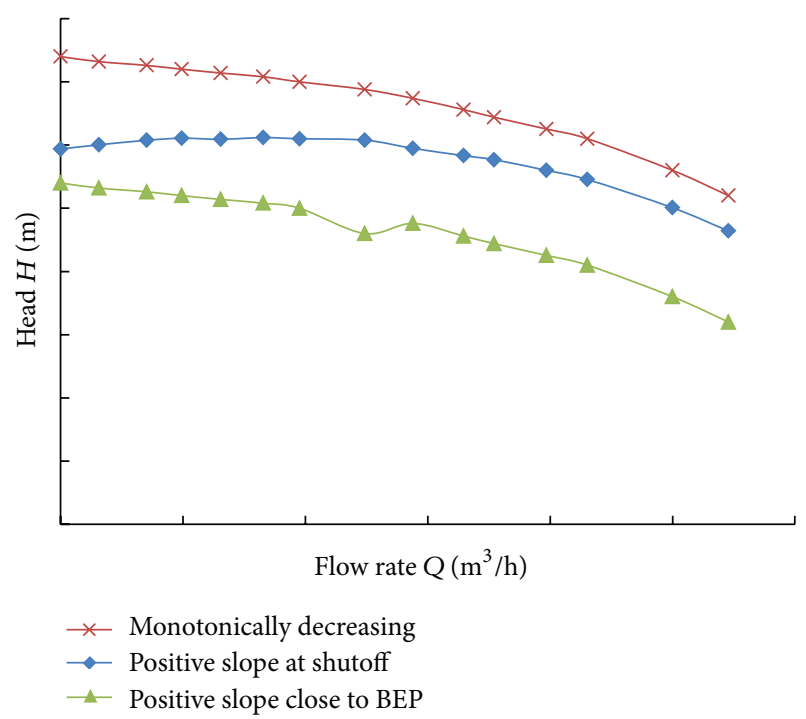

FIGURE 2: Typical pumping characteristics.

a head-flow performance curve. Three typical head-flow characteristics are presented in Figure 2. Curve 1 satisfies most end-users' needs for its characteristic of a monotonically negative slope. Curve 2 is a characteristic with a positive slope close to shutoff, which is caused by resistance at that operating point. The positive slope of characteristic occurs close to the best efficiency point (BEP) for curve 3 , which is typical for axial and mixed flow pumps and high specificspeed centrifugal pumps. A theoretical analysis was carried out by Greitzer to explain the fundamental mechanisms and characteristics of a rotating stall [14]. He concluded that a rotating stall is flow instability caused by a positive slope of the head-flow rate performance curve, whereby the rotational frequency of rotating stall depends on the performance and the geometry of the rotor. Miyabe et al. visualized the unsteady internal flow in diffuser with Dynamic PIV $[15,16]$. The authors clarified that the diffuser rotating stall causes the positive slope of a head-flow characteristic, and the backflow (i.e., a stall cell or a vortex) at the hub side of the diffuser plays an important role in the onset of a diffuser rotating stall. Anchored on the investigation of the behavior of a rotating stall in a diffuser mixed flow pump, Miyabe et al. enlarged the diameter of the hub at the diffuser inlet and found that the flow rate at which characteristic instability occurs is lower [15]. Pan et al. also enlarged the diameter of the hub at the diffuser inlet and obtained a similar result [10]. Although the method mentioned above does not suppress the positive slope of the head-flow performance curve completely, it still provides insight that an appropriate diffuser will eliminate the positive slope area while the rotating stall still occurs. That is, the situation quoted by Greitzer may also be found in pumps.

\section{Unstable Head-Flow Characteristic Generation Mechanism}

A typical positive slope of the head-flow performance curve close to BEP is represented in Figure 2 (curve 3), and 


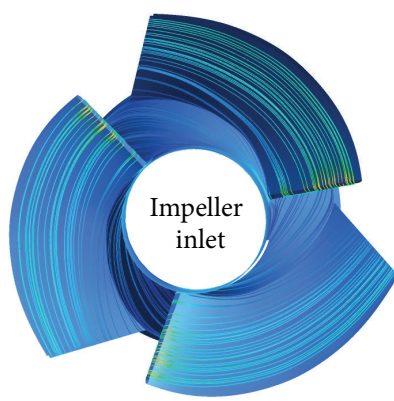

(a) $Q_{\mathrm{BEP}}$

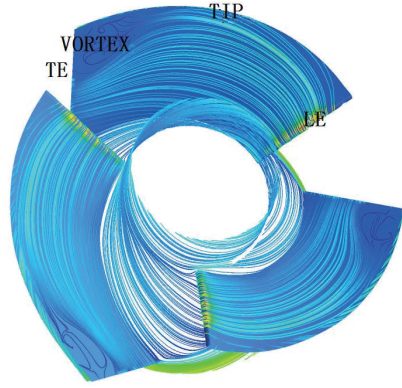

(b) $0.75 Q_{\mathrm{BEP}}$

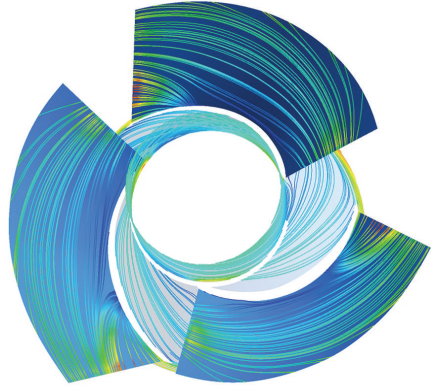

(c) $0.65 \mathrm{Q}_{\mathrm{BEP}}$

FIGURE 3: Velocity streamlines near the surface of impeller blades.

the mechanism of the head-flow curve instability can be explained as follows $[10,11,17]$. As shown in Figure 3, the streamline distribution near the blade surface is applied to provide a measure of flow separation and losses for the impeller [18]. At a partial flow rate, the flow angle decreases because of a tip leakage flow developed from the pressure surface (PS) to the suction surface (SS) near the trailing edge (TE) of the impeller; meanwhile, the generated vortices, which decrease the effective diameter of the impeller TE, mainly cause the abrupt head drop (Figure 3(b)). The prerotation upstream of the impeller LE at the casing also causes a decrease in pressure [19].

Further decrease in the flow rate causes the flow on the vane diffuser hub side to become unstable from the adverse pressure gradient and strong reserve flow. The reserve flow, which may change flow pattern in the impeller from the axial type to the centrifugal type and cause a slight increase of the head, returns to the impeller and blocks the passage flow from the impeller (Figure 3(c)).

To suppress the positive slope in a head-flow characteristic, feasibility should be studied to eliminate the three cases mentioned above. To investigate the flow structures and the head-flow curve instability for a mixed flow pump, a computation fluid dynamic is used in this study. The tested pump is a three-blade impeller and a seven-blade diffuser with a specific speed of $n_{s}=472$ at the best efficiency point $\left(n_{s}=\right.$ $3.65 n Q^{0.5} H^{-0.75} / 60, Q_{\text {BEP }}=887.76 \mathrm{~m}^{3} / \mathrm{h}, H=5.86 \mathrm{~m}, n=$ $980 \mathrm{r} / \mathrm{min}$ ). Figure 4 shows the computational model for this study, which involves suction casing, impeller, diffuser, and discharge casing. The tip clearance between the impeller and the casing with a clearance of $3 \mathrm{~mm}$ is also included. Relevant details on the pump geometry are shown in Figure 5.

The mesh is generated using the commercial software ICEM-CFD v12.0, a grid independence study used seven different sizes of grids with elements from $1,200,000$ to $2,400,000$ nodes. As the differences of the CFD results were less than $0.2 \%$ with the meshes having more than $1,800,000$ nodes and finer grid is needed to capture the flow structure, hence, the meshes with 2,000,000 nodes were adapted for the calculations.

In the present study, three-dimensional, steady and unsteady, Reynolds-averaged Navier-Stokes equations are solved by using the SST $k-\omega$ turbulence model derived by
Menter [20]. Boundary conditions and the convergence criteria of the steady flow simulation are set according to $[9,10]$. As for the unsteady calculation, 11 revolutions of the impeller for each operating condition in this case were conducted, and 3 deg of impeller rotation per step was adopted for the revolutions; therefore, 120 transient results are included for one impeller revolution. Within each time step, the number of iterations has been chosen to 15 , and the iteration stops when the RMS (root mean square) residual dropped below $4 \times 10^{-5}$. The inlet boundary condition is set to mass flow rate, while a constant total pressure (1.1 atm) in the stationary frame is applied as the outlet condition. The interface between the impeller and the diffuser is set to "transient rotor-stator" to capture the transient flow.

Figure 5 shows the experimental results of the head-flow performance in comparison with CFD results. The maximum difference between the two methods is \pm 4.8 percent, which indicates that the result of the CFD in this study is reliable.

\subsection{Factors for the Abrupt Head Drop}

3.1.1. Prerotation at the Impeller Inlet. Prerotation is assumed to be responsible for a head drop at part-load operating points, as proven in earlier studies [21]. Figure 6 shows the streamline at the upstream of the impeller, where prerotation occurs at partial flow rate. Muggli et al. used the standard $k-\varepsilon$ turbulence model to calculate a mixed flow pump characteristic from shutoff to maximum flow [19]. They clarified that the prerotation upstream of the impeller LE at the casing causes a decrease in pressure. However, more details on the drastic head drop were not presented. In other words, further study is needed to determine whether prerotation is an important factor in characteristic instability.

To analyze the influence of prerotation on the positive slope of the head-flow performance curve, a swirl-stop is placed upstream of the impeller. The velocity streamline of the impeller inlet with a swirl-stop is presented in Figure 7.

Head curves with two different conditions are presented in Figure 8. Although prerotation is eliminated at $0.75 Q_{\mathrm{BEP}}$ in the presence of the swirl-stop, the positive slope region does not disappear. As the prerotation appears at $0.65 \mathrm{Q}_{\mathrm{BEP}}$, the influence of the swirl-stop on pump performance at this point cannot be concluded. The prerotation may be no more than 


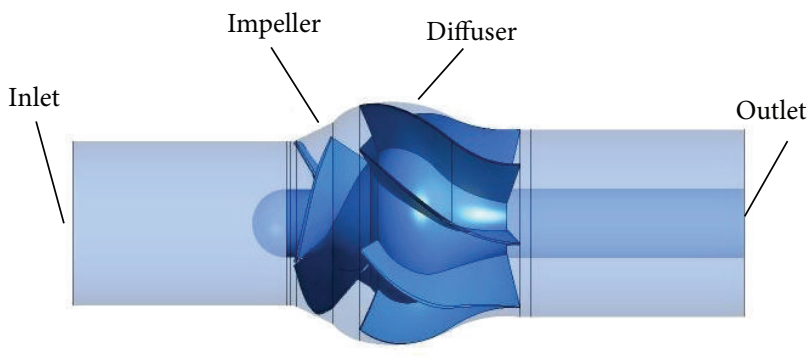

(a) Computation domain

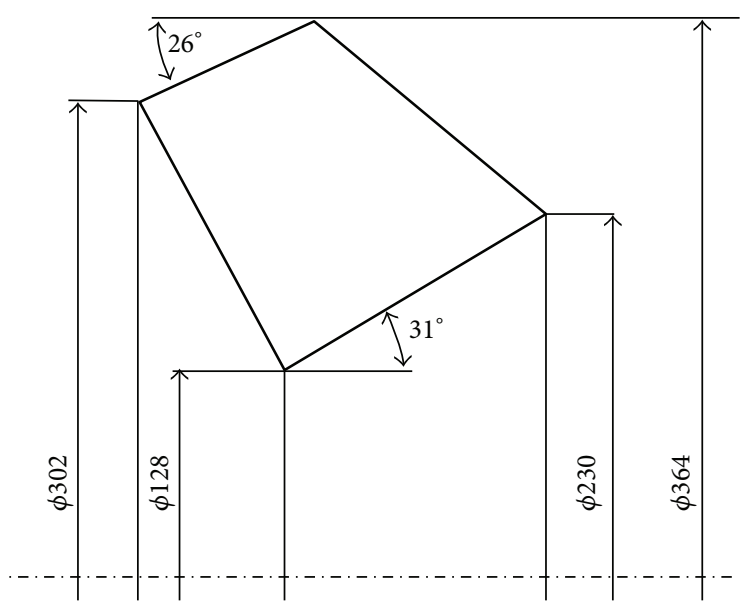

(b) Meridian plane of impeller

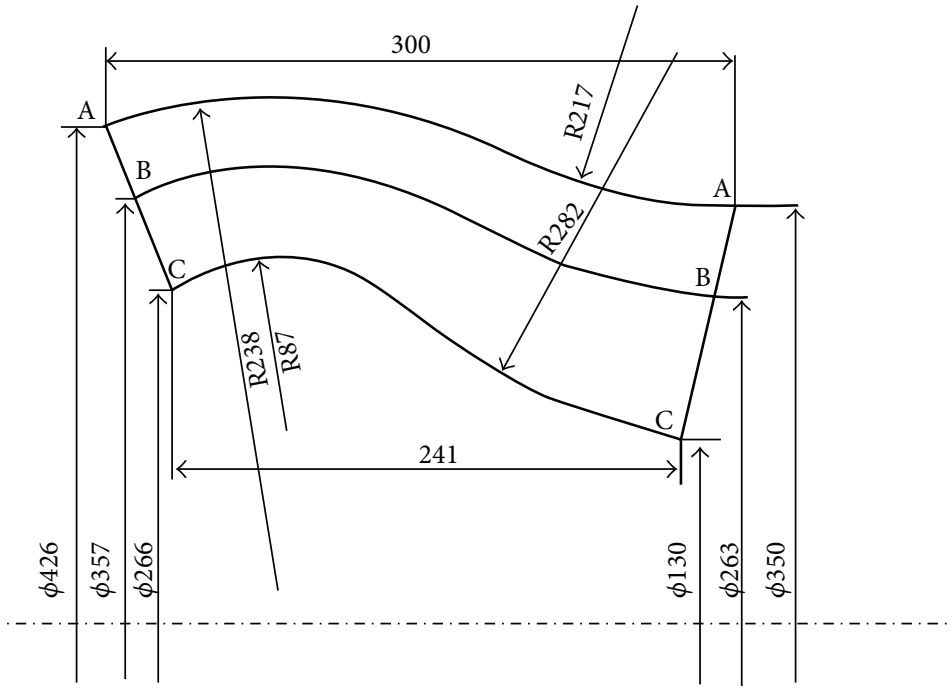

(c) Meridian plane of diffuser

Figure 4: Overview of the investigated pump.

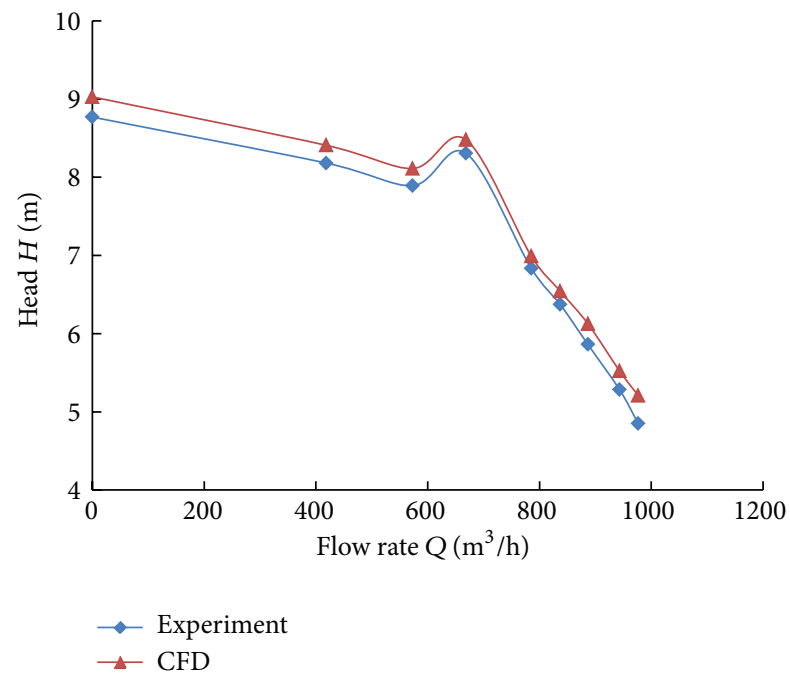

FIGURE 5: Measured and calculated head (total pressure) curves. the result of flow rate change rather than the reason for the positive slope of the head-flow performance curve. Therefore, eliminating the prerotation of the impeller inlet is not a viable approach for inhibiting the performance curve instability.

The following examples can support the above mentioned conclusion. Sinha et al. used a converging nozzle and a flow straightener (honeycombs and screen) at the entrance of a centrifugal pump with a vane diffuser to smooth the inflow: no rotating stall was found in the impeller compared with that in a vane passage at the beginning of the volute, and the abrupt head drop occurred at $0.51 Q_{\mathrm{BEP}}$ [22]. To suppress the rotating stall in the diffuser, Miyabe et al. enlarged the diameter of the hub at the diffuser inlet and placed a swirl stop at the pump entrance. The positive slope of the head-flow performance still occurred at partial flow rate [16].

3.1.2. Leakage Flow in the Tip Clearance. Figure 9 shows the flow pattern in the tip clearance. The leakage flow flows from the PS to the SS, and the interaction between the leakage flow 


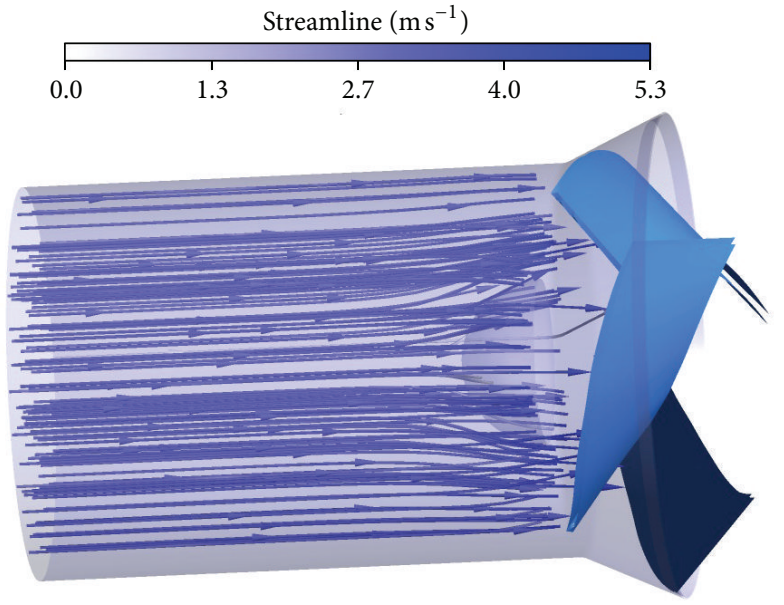

(a) $Q_{B E P}$

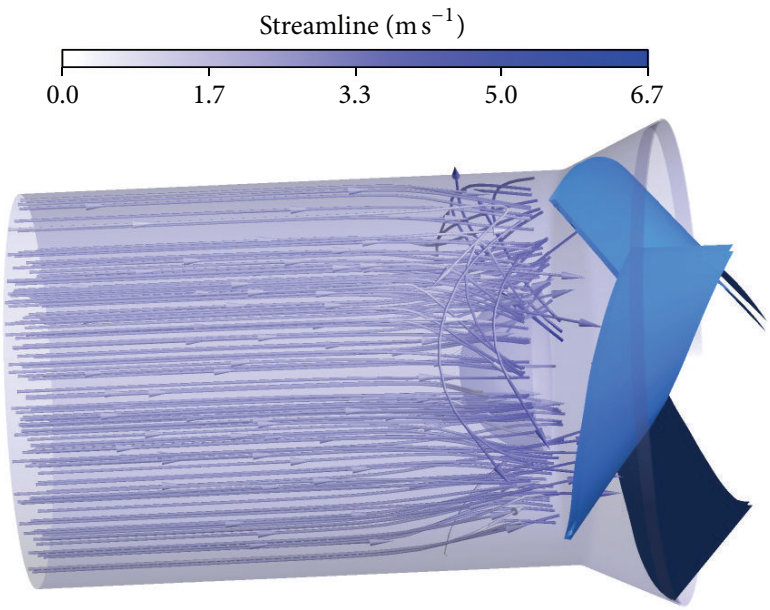

(b) $0.75 Q_{\mathrm{BEP}}$

FiguRE 6: Velocity streamline at the upstream of the impeller.

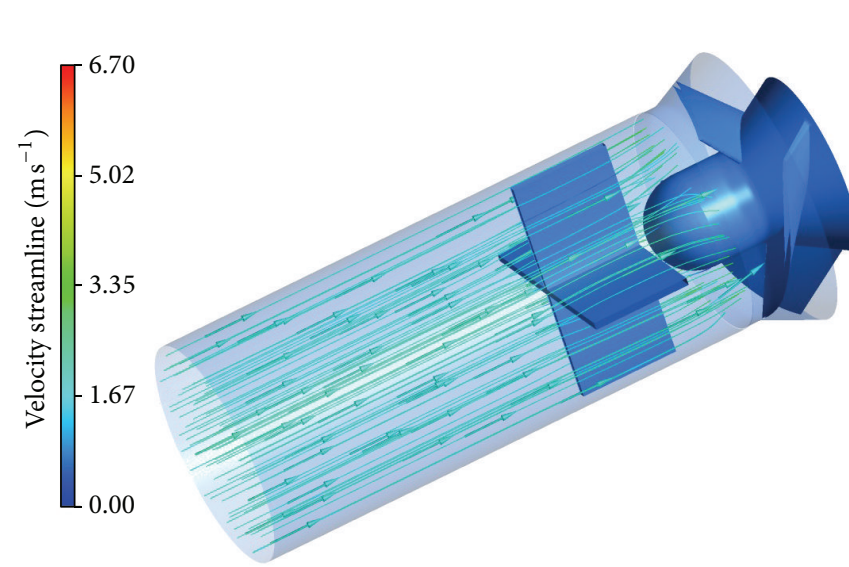

(a) $0.75 Q_{\mathrm{BEP}}$

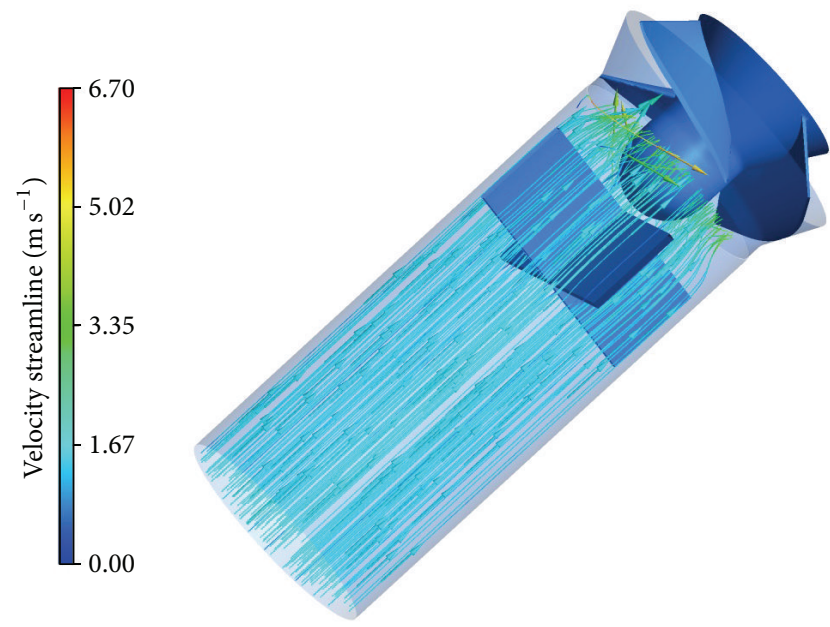

(b) $0.65 Q_{\mathrm{BEP}}$

FIgURE 7: Velocity streamline at the upstream of the impeller with a swirl-stop.

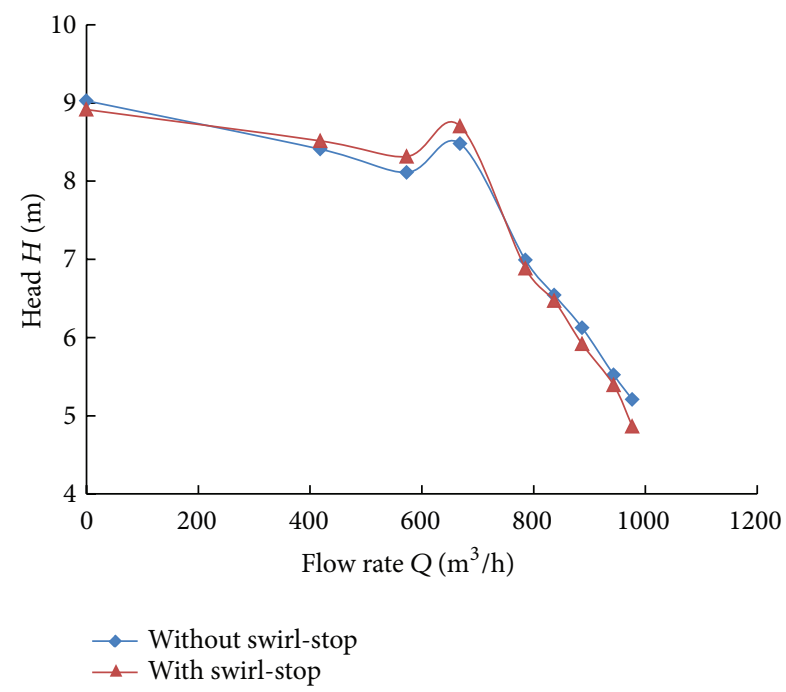

FIGURE 8: Head curves of the pump with and without swirl-stop. in the tip clearance and the passage flow in the impeller generates a vortex. The leakage flow gradually increases, and a separate flow is generated on the suction surface with the decreasing flow. Yamade et al. also clarified that the drastic change of flow structures at the impeller outlet has a significant effect on the positive slope of the head-flow performance curve [23].

A mixed flow pump without tip clearance is then adopted to analyze the influence of leakage flow on the positive slope of the head-flow performance curve. The predicted pump characteristic is plotted in Figure 10, which is compared with the numerical simulation result of a conventional pump. The positive slope region is shown to be eliminated for the pump without tip clearance. Moreover, a positive slope region is not seen in the head-flow characteristic at $0.75 Q_{\mathrm{BEP}}$, which appears in the case of a conventional pump.

The velocity streamlines of the impeller blade surface and the impeller inlet at $0.75 Q_{\mathrm{BEP}}$ are shown in Figure 11 . The vortices caused by the leakage flow near the TE of the impeller tip have been suppressed, and prerotation at the impeller inlet 


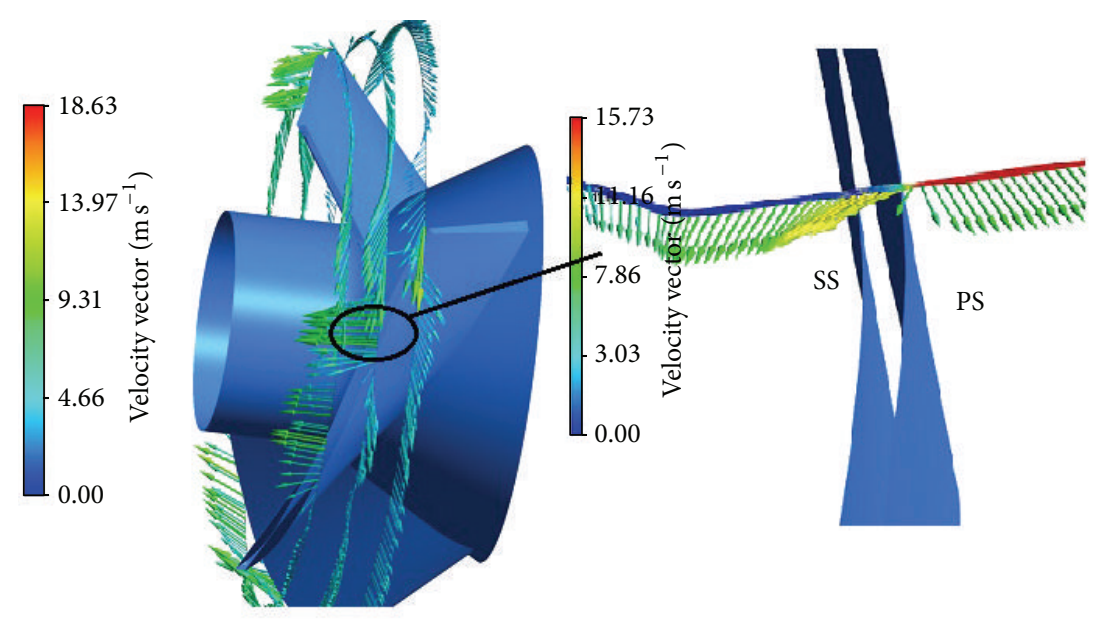

FIGURE 9: Relative velocity vectors of the leakage flow in the tip clearance at $0.75 Q_{\mathrm{BEP}}$.

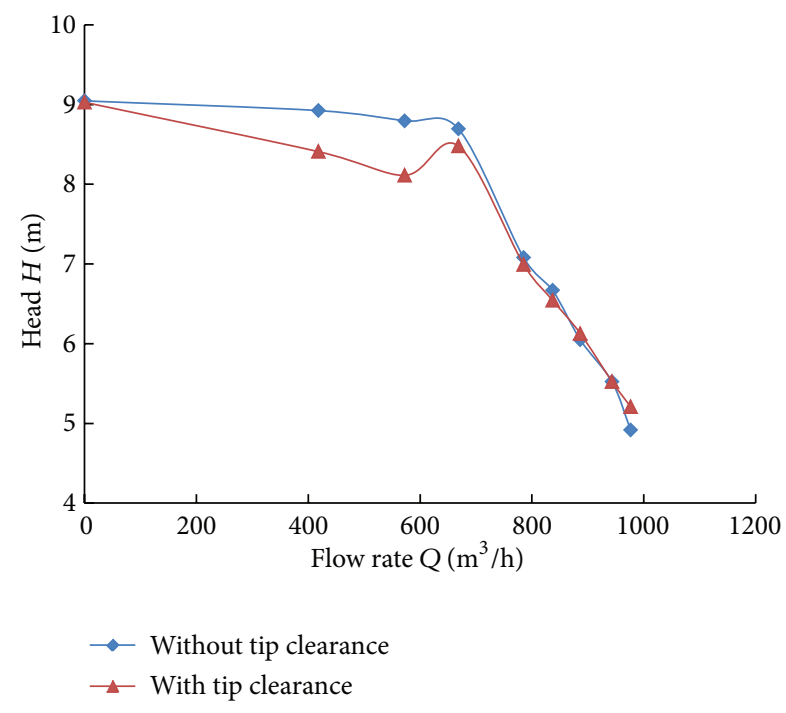

FIGURE 10: Head curves of the pump with and without tip clearance.

are also restricted in comparison with Figures 3(b) and 6(b). As the prerotation at the impeller inlet has no obvious effect on the positive slope of the head-flow performance curve, the vortices caused by leakage flow near the TE of the impeller tip can be concluded as the main reason for the abrupt head drop.

Although the mixed flow pump without tip clearance has a stable head-flow characteristic, this pump cannot be produced, as the gap between the impeller tip and the casing is a necessity to ensure the normal operation of the pump. In fact, zero leakage in the tip clearance is the reason that the head-flow characteristic of a mixed flow pump is stable, that is, tangential velocity of the leakage flow is zero in this case. Certain methods could be used to minimize the velocity of the leakage flow, which will suppress the positive slope of the head-flow performance curve despite the presence of the tip clearance. Installing shallow grooves on the casing wall near the impeller tip is such a method.
Figure 12 shows the velocity streamline in the shallow groove at $0.75 Q_{\mathrm{BEP}}$. Two kinds of grooves are presented. JGroove, the shallow groove installed in the axial direction on the casing wall, has a rectangular cross-sectional area. Both J-Grooves have the same configuration with 30 grooves, each with a width of $4 \mathrm{~mm}$ and length of $45 \mathrm{~mm}$; the depths of the grooves differ. Groove 1 has a depth of $4 \mathrm{~mm}$, and Groove 2 has a depth of $2 \mathrm{~mm}$.

J-Grooves can suppress the rotating stall by controlling mainstream angular momentum. Although the grooves are very shallow, the decrease in the tangential velocity of the leakage flow is significant. As seen in Figure 12, Groove 1, which has a lower velocity of groove flow, can suppress the head-flow characteristic instability (Figure 12(b)). With the decrease in depth, the ability of the J-Grooves to control the angular momentum of the main flow is weakened. Thus, Groove 2, which is half as deep as Groove 1, has less effect on the positive slope of the head-flow performance curve (Figure 12(c)).

3.2. Factors for the Slight Rise of the Head. As mentioned above, reserve flow occurring near the inlet of the hub surface of the vane diffuser is the main reason for the slight rise of the head-flow characteristic instability. To illustrate this phenomenon, the internal flow in the vane diffuser at different flow rates is analyzed and then presented in Figure 13.

The slope of the performance curve changes at $0.75 Q_{\mathrm{BEP}}$; a vortex is generated at the tip of the impeller outlet, and the reverse flow occurs near the TE of the diffuser (Figures $3(b)$ and $13(c)$ ). As the flow rate decreases further, a strong vortex is generated near the inlet of the hub surface of the vane diffuser, and the velocity profiles change at both the inlet and outlet of the impeller. Reverse flow takes place at the inlettip and outlet-hub, and the flow pattern changes from the axial type to centrifugal type in the passage of the impeller, which leads to a slight increase of the head-flow characteristic instability. As in [24], the current study ignores the detail of 


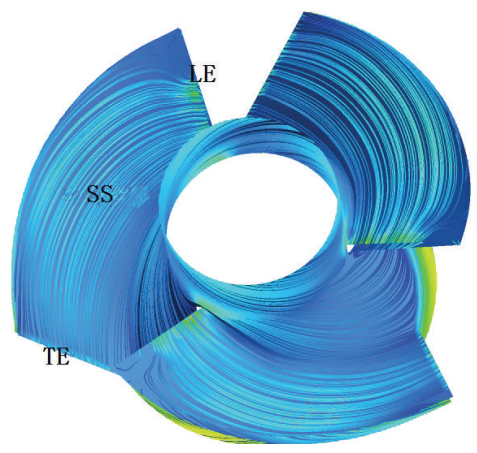

(a)

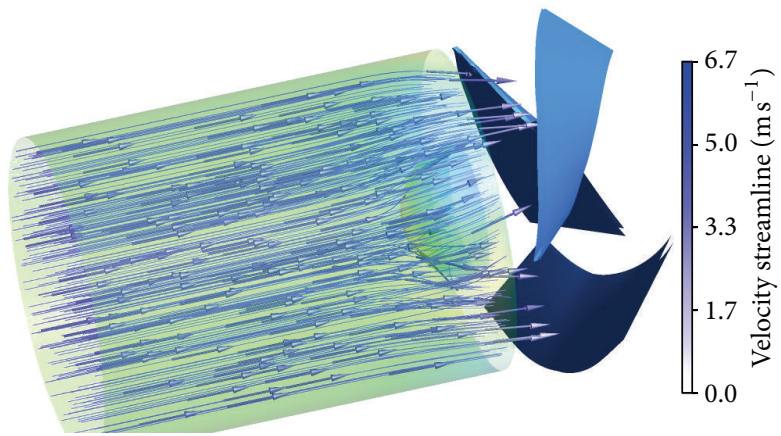

(b)

FIGURE 11: Velocity streamlines of the pump without tip clearance at $0.75 Q_{\mathrm{BEP}}$

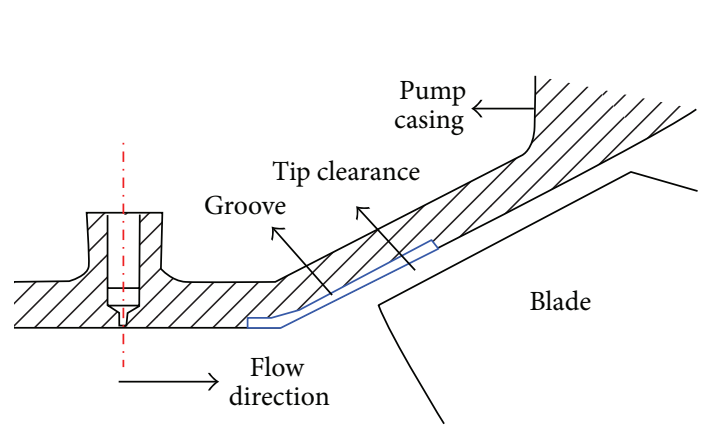

(a) Location of grooves

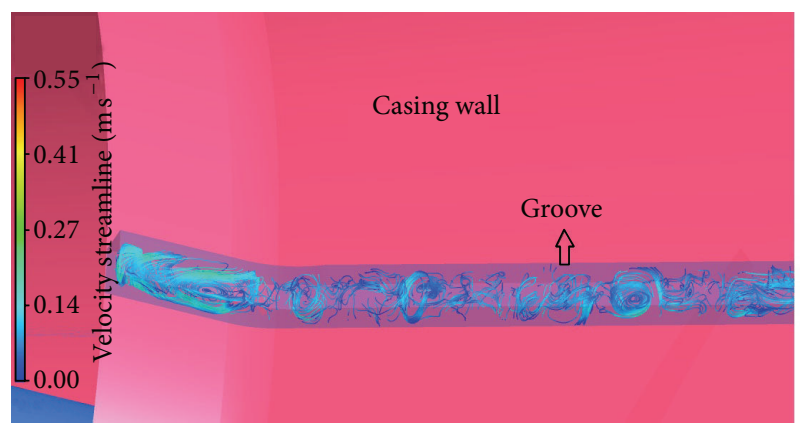

(b) Groove 1

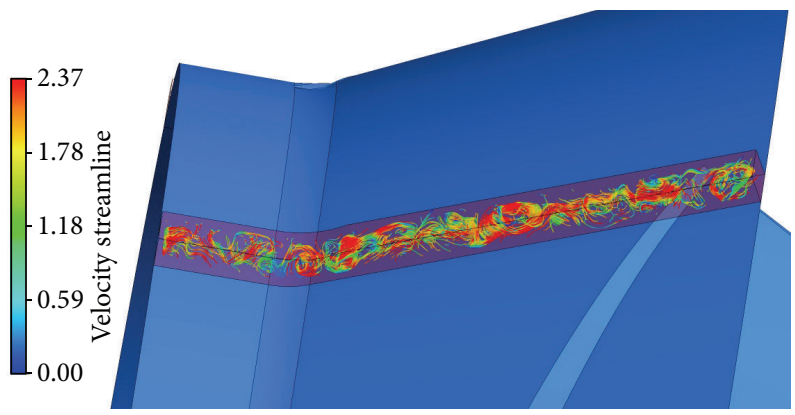

(c) Groove 2

FIGURE 12: Velocity streamlines in the shallow groove $\left(0.75 Q_{\mathrm{BEP}}\right)$.

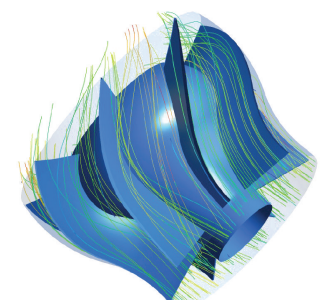

(a) $1.1 Q_{\mathrm{BEP}}$

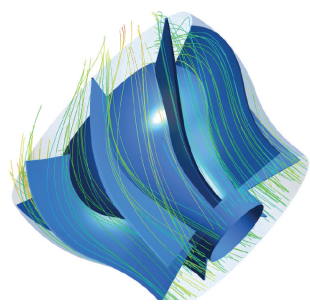

(b) $Q_{B E P}$

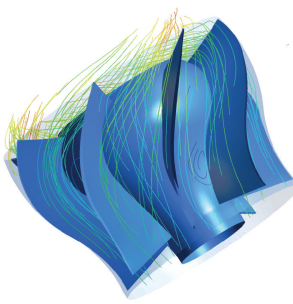

(c) $0.75 Q_{\mathrm{BEP}}$

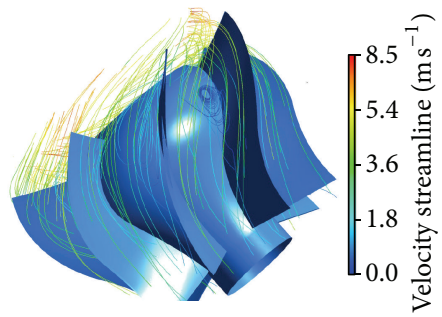

(d) $0.65 Q_{\mathrm{BEP}}$

FIGURE 13: Three-dimensional streamlines in the vane diffuser. 


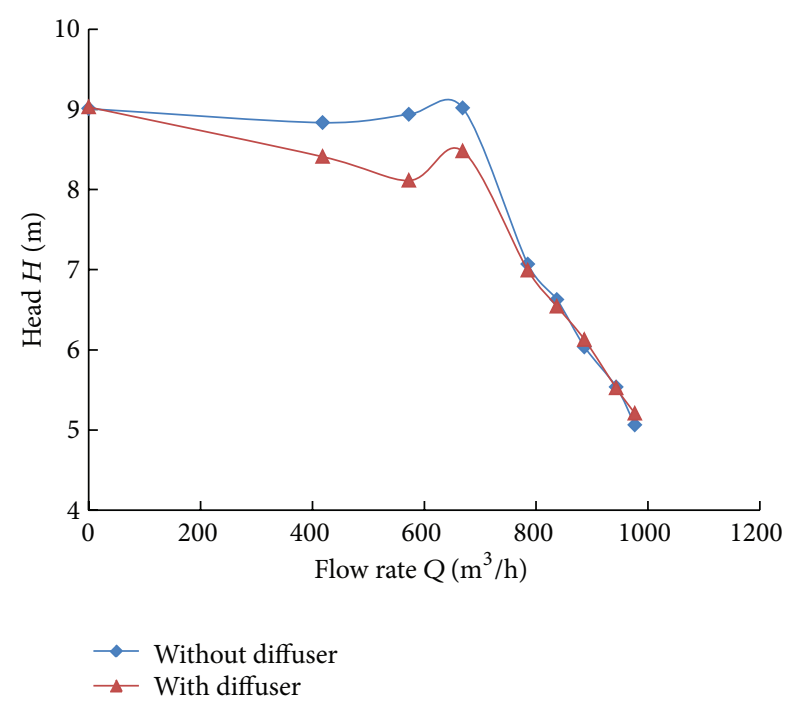

FIGURE 14: Comparison of performance curve when the pump is with and without diffuser.

the rotating stall although the instabilities are related to the stall behavior.

To verify the relation between the head-flow characteristic instability and the flow structure in the diffuser, the diffuser is removed and a new pump is obtained. The predicted pump characteristic is presented in Figure 14, which shows that the pump head is higher than the conventional one over the entire flow rate range. Energy loss is generated when the fluid flows through the diffuser, and interaction between the impeller and the diffuser also causes an energy loss. At partial flow rates, an abrupt head drop appears on the head curve at $0.75 Q_{\mathrm{BEP}}$, but the region of slight head rise is eliminated at $0.65 Q_{\mathrm{BEP}}$.

Figure 15 presents the velocity streamlines at the meridional section of the impeller passage without a diffuser; the reserve flow region at the TE of the impeller hub is restricted in comparison with that in Figure 3(c). The reserve flow at the outlet of the impeller is caused by a strong vortex at the LE of the diffuser that blocks the downstream flow from the impeller. Further study on flow patterns of the diffuser may help reveal the mechanism of the slight rise in the head-flow characteristic instability.

\section{Dynamic Characteristics of Rotating Stall within the Diffuser}

Several studies have focused on the relationship between pump characteristic instability and internal flow in a pump. The positive slope of head-flow performance curve mentioned in Section 3 is an example of this research inquiry. As for the pump with a diffuser, the diffuser rotating stall causes the positive slope of head-flow characteristic, and the backflow at the hub side of the diffuser plays an important role in the onset of the diffuser rotating stall $[9,15,25]$. The onset and developed state of rotating stalls within a vane diffuser was illustrated in Section 2. However, Ogata and
Ichiro found that the propagation mechanism of a stall cell from one vane passage to another is more complex than that covered in the conventional explanation [26]. The inception of characteristic instability can be analyzed as follows [15, 22]: at partial flow rate, low energy fluids are accumulated in the corner between the hub surface and the convex surface of the diffuser vane. As the flow rate further decreases, the region of low energy fluids at the corner axis asymmetrically expands along the hub and becomes unstable because of the adverse pressure gradient. Then, strong backflow occurs, which impinges against passage flow from the impeller at the inlet of the vane diffuser. Therefore, flow separation occurs near the inlet of the vane diffuser, and a stall is generated.

4.1. Effect of Flow Rate and Onset of the Stall. Figure 16 shows the contour of axial velocity distributed at the cross-sections of the vane diffuser at partial flow rates. The flow rates are selected to show the transition of decreasing flow rate from a flow where no stall occurs to conditions of massive stall in the diffuser passage. At $0.8 Q_{\mathrm{BEP}}$, the flow is clearly not stalled, compared with the head-flow curve provided in Figure 5. With the decrease in the flow rate, an obvious difference is seen in the axial velocity and the static pressure distribution between adjacent diffuser passages (Figures 16(b) and 17(b)), which may be the reason for the flow separation near the outlet of the vane diffuser, shown in Figure 13(c). As the flow further decreases, the axial velocity becomes negative in the corner between the hub surface and the suction surface of the diffuser inlet at $0.65 Q_{\mathrm{BEP}}$, hence, flow separates from the suction surface at the LE of the diffuser, and the stall core is generated (Figures 13(d) and 16(d)).

4.2. Propagation Mechanism of a Rotating Stall. As seen in Figure 17, the adverse pressure gradient is increased in the diffuser passage where a stall is developed. A difference in static pressure distribution is observed in the adjacent diffuser passages at partial flow rates, but the detailed flow pattern is far more than is known. Relative velocity vectors near the LE of the diffuser is presented at $0.65 Q_{\mathrm{BEP}}$ where a vortex is developed toward the inlet of the diffuser and blocks the passage flow from the impeller, near the diffuser inlet. The adverse pressure gradient is then increased in the diffuser passage, which causes the strong reserve flow in the entire area of one diffuser passage (Figures 16(d) and 18(a)).

In our previous studies, we found that the propagation mechanism and onset of rotating stall are more complicated than described in the classical explanation. The stall is not only affected by the inlet flow but also influenced by the outlet flow, as well as the pressure gradient in the flow passage. The nonuniform pressure distribution in the diffuser outlet or inlet causes the stall to propagate [11]. Sinha et al. attributed the nonuniform pressure distribution in the diffuser inlet to high-speed leakage flow (jet-flow) in the gap between the impeller and the diffuser [22]. Yoshida et al. observed a seven-bladed centrifugal impeller operating with a variety of diffusers with and without vanes. Rotating stall occurs in the vane diffuser at a speed less than $10 \%$ of the impeller speed. The clearance between the impeller and the diffuser vanes is 

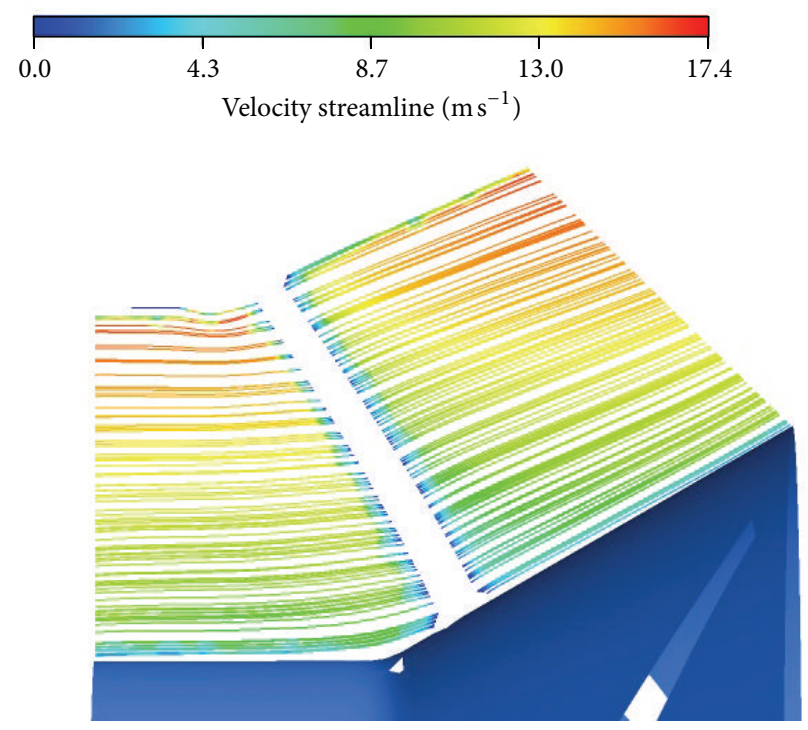

(a) $1.0 Q_{\mathrm{BEP}}$
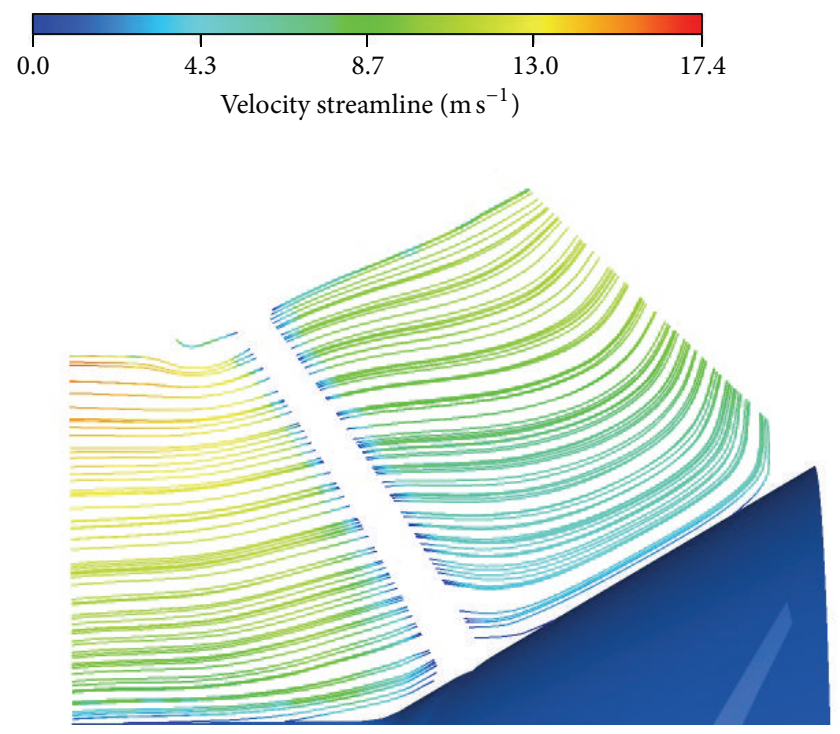

(b) $0.65 Q_{\mathrm{BEP}}$

FIGURE 15: Velocity streamlines at the meridional section of impeller the passage without diffuser.

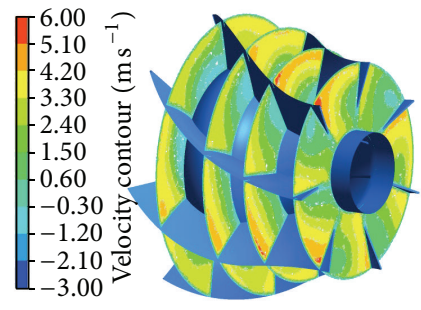

(a) $0.8 Q_{\mathrm{BEP}}$

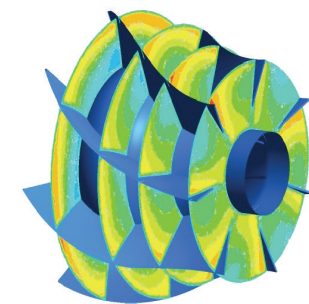

(b) $0.75 Q_{\mathrm{BEP}}$

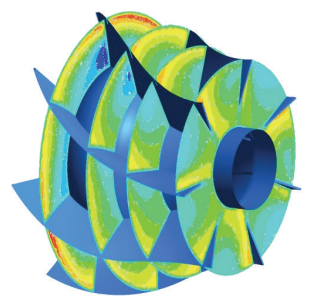

(c) $0.7 \mathrm{Q}_{\mathrm{BEP}}$

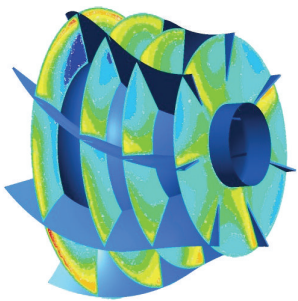

(d) $0.65 Q_{\mathrm{BEP}}$

FIGURE 16: Axial velocity contour in the vane diffuser at partial flow rate.

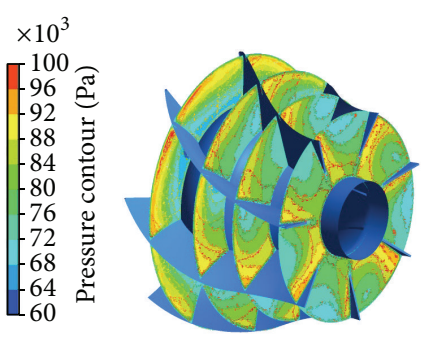

(a) $0.8 Q_{\mathrm{BEP}}$

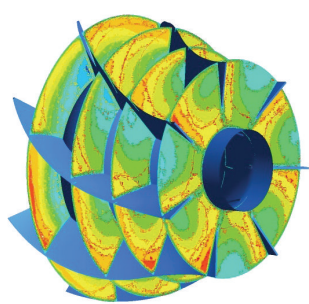

(b) $0.75 Q_{\mathrm{BEP}}$

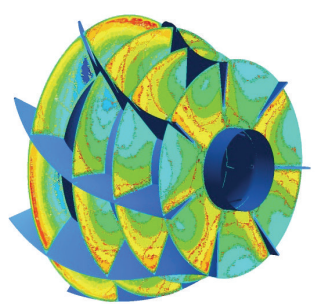

(c) $0.7 Q_{\mathrm{BEP}}$

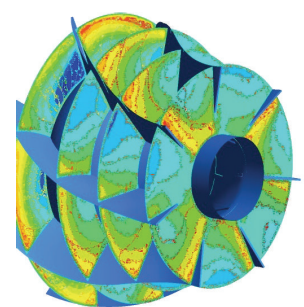

(d) $0.65 \mathrm{Q}_{\mathrm{BEP}}$

Figure 17: Pressure contour in the vane diffuser at partial flow rate.

large. As this clearance decreases, the diffuser rotating stall tends to disappear [27]. The jet flow also occurs near the TE of the vane, and alternate jet flow and reverse flow appear when a rotating stall occurs, as shown in Figure 19.

As the propagation mechanism and onset of rotating stall is more complicated than described in the classical explanation, an accurate propagation velocity is difficult to achieve. The speed is clearly a fraction of the circumferential component of the relative velocity, that is, either $v_{\theta 1}$ in the case of a stator or $w_{\theta 1}$ in the case of a rotor. In the case of a rotor, the stall rotates in the same direction as the rotor but with $50 \%$ to $70 \%$ (other reports indicate $50 \%$ to $90 \%$ ) of the rotor angular velocity. In the case of a stator, the fraction is between $10 \%$ and 25\% [9, 12]. Figure 20 shows a period of stall propagation at $0.65 Q_{\mathrm{BEP}}$, where the propagation speed is about $20 \%$ of the impeller speed. Additional information cannot be obtained as the stall does not finish one complete circle of propagation. 


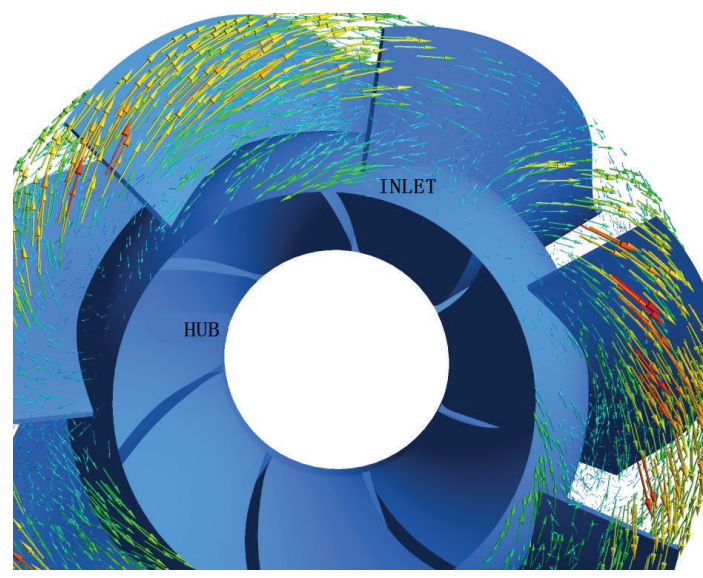

(a) Velocity vectors

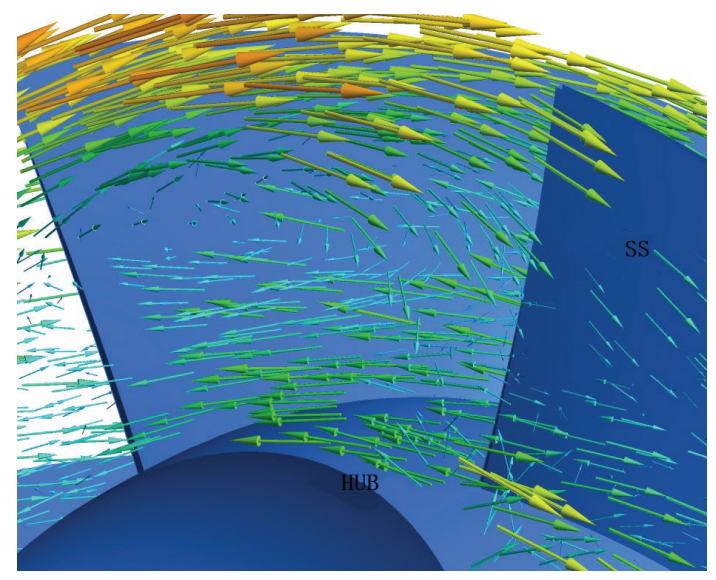

(b) Velocity vectors (enlarged)

FIGURE 18: Relative velocity vectors near the $L E$ of diffuser at $0.65 Q_{\mathrm{BEP}}$.

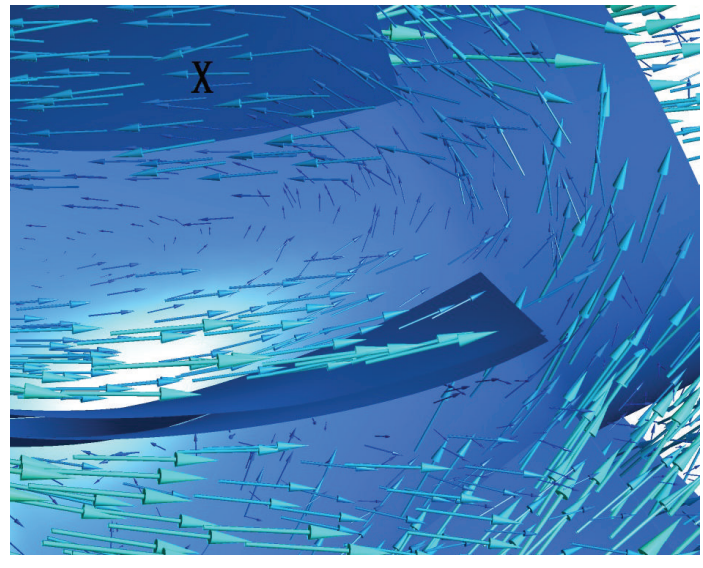

(a) Reverse flow at the vane outlet

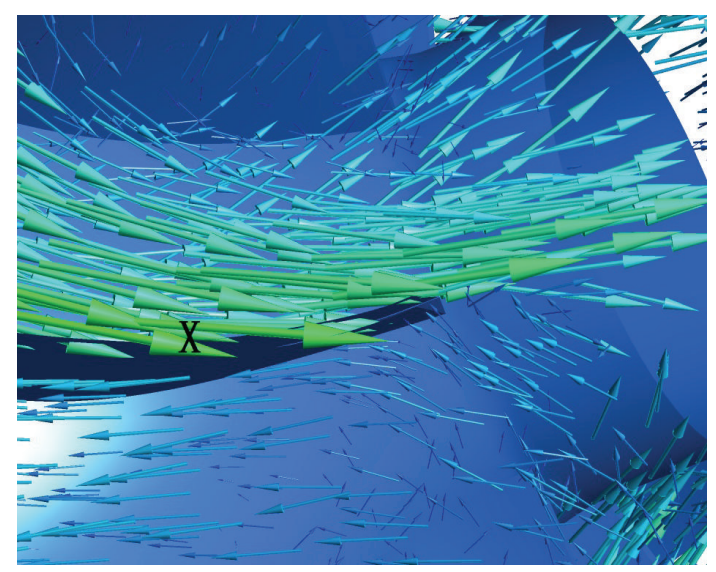

(b) Jet-flow at the vane outlet

FIGURE 19: Instantaneous velocity vectors near the TE of the diffuser at $0.65 Q_{\mathrm{BEP}}$.

\section{Conclusions}

(1) The appearance of pump characteristic instability is associated with the unstable flow pattern at partial flow rate. The leakage flow occurs at the tip clearance between the casing and the impeller. The reserve flow at the inlet of the diffuser contributes to the headflow characteristic instability. Prerotation may cause a head drop, but it has no effect on the positive slope of a head-flow performance curve.

(2) At partial flow rate, the flow angle decreases because of the leakage flow near the LE of the impeller tip and generated vortices, which are the main reason to the abrupt head drop. This conclusion is verified by the pump without tip clearance and by the J-Grooves mounted on the casing.

(3) The flow pattern in the impeller changes from the axial type to the centrifugal type because of the reserve flow near the inlet of the hub surface of the vane diffuser. The stall is generated at the diffuser inlet and causes a slight increase of the head-flow characteristic instability.

(4) The propagation mechanism and onset of rotating stalls are more complicated than described in the classical explanation. A rotating stall is not only effected by the inlet flow but also influenced by the outlet flow, as well as the pressure gradient in the flow passage. The pressure phase determines the stall propagation. However, the factor that determines the pressure phase is a further concern.

(5) Alternate jet-flow and reverse flow appear in the passage of a diffuser or an impeller when a rotating stall occurs. The nonuniform pressure distribution in the impeller/diffuser outlet or inlet causes the stall to propagate. Lower identical frequencies exist and are dependent on flow rate and rotational speed. A discrepancy is observed in the performance curve, and as a result, it is believed that the pump is closed to the onset condition of a rotating stall. 


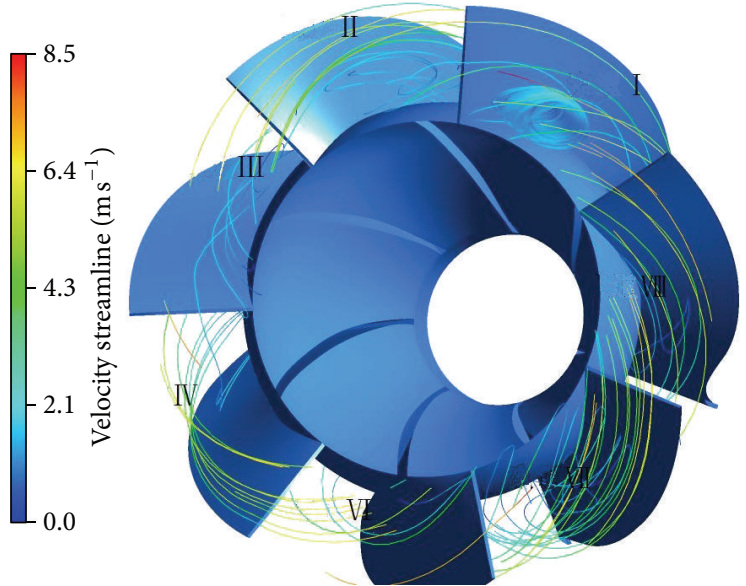

(a) $t=5 / 7 \mathrm{~T}$

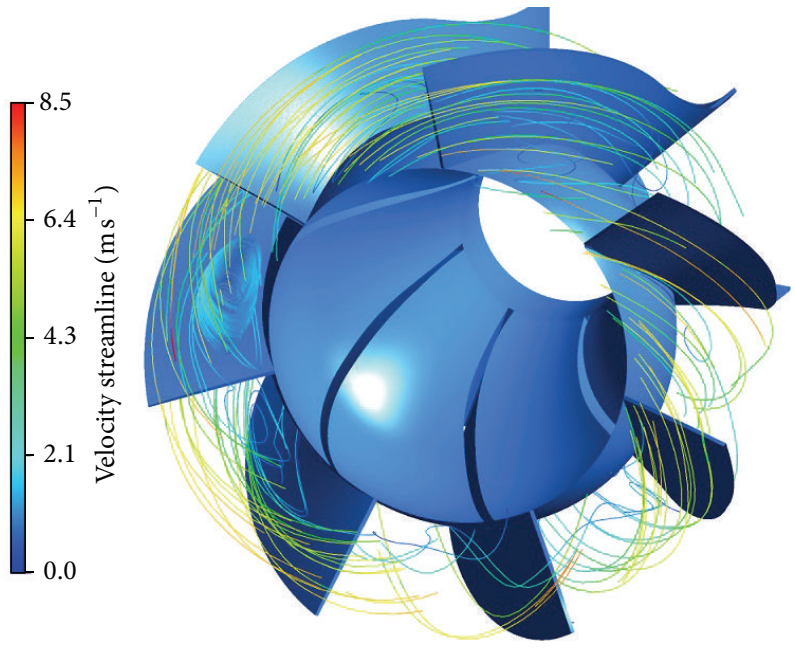

(c) $t=15 / 7 \mathrm{~T}$

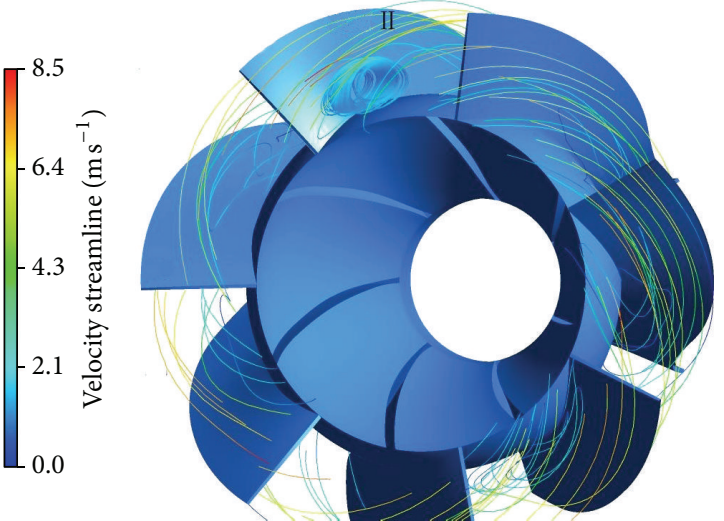

(b) $t=10 / 7 \mathrm{~T}$

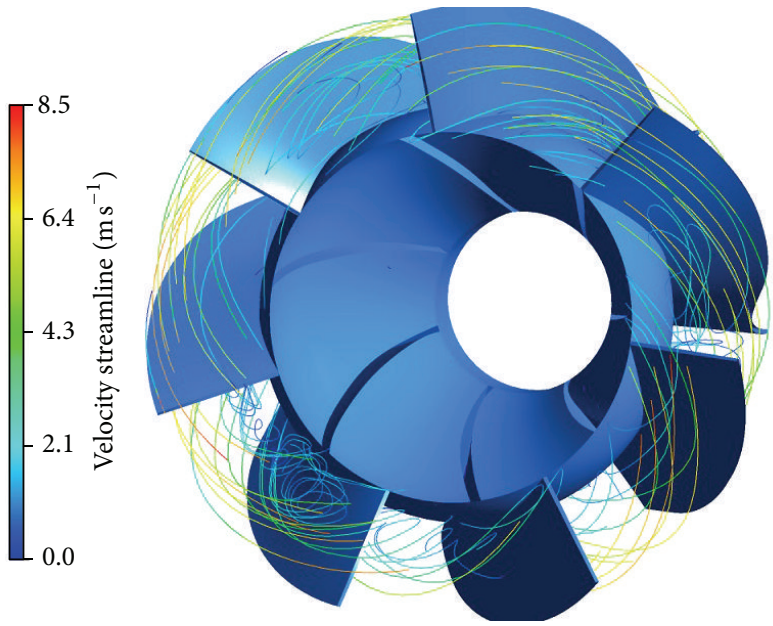

(d) $t=20 / 7 \mathrm{~T}$

FIgURE 20: Period of stall propagation at $0.65 Q_{\mathrm{BEP}}$.

\section{Acknowledgments}

This work was supported by the National Natural Science Foundation of China (Grant Nos. 51076144 and 51239005), National Science and Technology Pillar Program of China (Grant no. 2011BAF14B04), and Jiangsu Provincial Projects for Innovative Postgraduates of China (Grant no. CXZZ11_0564). The support provided by these institutions is gratefully acknowledged.

\section{References}

[1] S. Gopalakrishnan, "Pump research and development: past, present, and future-an American perspective," ASME Journal of Fluids Engineering, vol. 121, no. 2, pp. 237-253, 1999.

[2] Z. Y. Pan, Y. Y. Ni, J. Ho, and S. Q. Yuan, "Flow structures and pressure fluctuations in a centrifugal pump at design and off-design conditions," in Proceedings of the ASME Fluids Engineering Division Summer Conference (FEDSM '09), pp. 137145, Vail, Colo, USA, August 2009.
[3] S. Q. Yuan, J. Yang, J. P. Yuan, Y. Luo, and J. Pei, "Measurement on the flow-induced noise under variable conditions for centrifugal pumps," Chinese Journal of Mechanical Engineering, vol. 25, pp. 456-462, 2012.

[4] Y. Y. Ni, S. Q. Yuan, Z. Y. Pan, and J. P. Yuan, "Detection of cavitation in centrifugal pump by vibration methods," Chinese Journal of Mechanical Engineering, vol. 21, no. 5, pp. 46-49, 2008.

[5] T. Yamamoto, J. Ho, and Z. Y. Pan, "Development of pump performance monitor (Part I)," in Symposium on Evaluation and Diagnosis (Section 5). Japan, pp. 105-112, 2005.

[6] Z. Y. Pan, J. J. Li, S. Li, and S. Q. Yuan, "Study on radial forces of centrifugal pumps with various collectors," in Proceedings of the ASME-JSME-KSME Joint Fluids Engineering Conference, Hamamatsu, Japan, 2011.

[7] S. Q. Yuan, Y. Y. Ni, Z. Y. Pan, and J. P. Yuan, "Unsteady turbulent simulation and pressure fluctuation analysis for centrifugal pumps," Chinese Journal of Mechanical Engineering, vol. 22, no. 1, pp. 64-69, 2009.

[8] Z. Y. Pan, J. J. Li, H. Li, and W. Liu, "Overview for research on rotating stall of pump," Fluid Machinery, vol. 39, pp. 35-39, 2011. 
[9] Z. Y. Pan, J. J. Li, X. J. Li, and S. Q. Yuan, "Performance curve instability and rotating stall," Transactions of the Chinese Society for Agricultural Machinery, vol. 43, pp. 64-68, 2012.

[10] Z. Y. Pan, T. T. Wu, J. J. Li, and Y. J. Li, "Mechanism of characteristic instability and its suppression in mixed flow pump," Transactions of the Chinese Society for Agricultural Machinery International Journal of Comprehensive Engineering C, vol. 1, pp. 1-7, 2012.

[11] S. Q. Yuan, W. Liu, Z. Y. Pan, and X. J. Li, "Review on rotating stall in pumps," Transactions of the Chinese Society for Agricultural Machinery International Journal of Comprehensive Engineering C, vol. 1, pp. 28-38, 2012.

[12] N. Krause, K. Zähringer, and E. Pap, “Time-resolved particle imaging velocimetry for the investigation of rotating stall in a radial pump," Experiments in Fluids, vol. 39, no. 2, pp. 192-201, 2005.

[13] H. W. Emmons, C. E. Pearson, and H. P. Grant, "Compressor surge and stall propagation," ASME Journal of Fluids Engineering, vol. 79, pp. 237-253, 1955.

[14] E. M. Greitzer, "The stability of pumping systems-the 1980 Freeman scholar lecture," ASME Journal of Fluids Engineering, vol. 103, no. 2, pp. 193-242, 1981.

[15] M. Miyabe, A. Furukawa, H. Maeda, I. Umeki, and Y. Jittani, "On improvement of characteristic instability and internal flow in mixed flow pumps," Journal of Fluid Science and Technology, vol. 3, pp. 732-743, 2008.

[16] M. Miyabe, A. Furukawa, H. Maeda, and I. Umeki, "Rotating stall behavior in a diffuser of mixed flow pump and its suppression," in Proceedings of the ASME Fluids Engineering Division Summer Conference (FEDSM '08), pp. 1147-1152, Jacksonville, Fla, USA, August 2008.

[17] M. Miyabe, H. Maeda, I. Umeki, and Y. Jittani, "Unstable headflow characteristic generation mechanism of a low specific speed mixed flow pump," Journal of Thermal Science, vol. 15, no. 2, pp. 115-144, 2006.

[18] H. W. Oh, "Design parameter to improve the suction performance of mixed-flow pump impeller," Proceedings of the Institution of Mechanical Engineers A, vol. 224, no. 6, pp. 881887, 2010.

[19] F. A. Muggli, P. Holbein, and P. Dupont, "CFD calculation of a mixed flow pump characteristic from shutoff to maximum flow," ASME Journal of Fluids Engineering, vol. 124, no. 3, pp. 798-802, 2002.

[20] F. R. Menter, "Two-equation eddy-viscosity turbulence models for engineering applications," AIAA journal, vol. 32, no. 8, pp. 1598-1605, 1994.

[21] R. Xie, Z. Y. Pan, J. J. Li, and J. R. Liu, "Influences of various inlet flow structure on the pump performance," in Proceedings of the 3 rd International Conference on Information and Computing, ICIC 2010, vol. 2, pp. 86-89, Wuxi, China, June 2010.

[22] M. Sinha, A. Pinarbasi, and J. Katz, "The flow structure during onset and developed states of rotating stall within a vaned diffuser of a centrifugal pump," ASME Journal of Fluids Engineering, vol. 123, no. 3, pp. 490-499, 2001.

[23] Y. Yamade, C. Kato, H. Shimizu, and T. Nagahara, "Large eddy simulation of internal flow of a mixed-flow pump," in Proceedings of the ASME Fluids Engineering Division Summer Conference (FEDSM '09), pp. 407-416, Vail, Colo, USA, August 2009.
[24] R. K. Byskov, C. B. Jacobsen, and N. Pedersen, "Flow in a centrifugal pump impeller at design and off-design conditionspart II: large eddy simulations," ASME Journal of Fluids Engineering, vol. 125, no. 1, pp. 73-83, 2003.

[25] S. H. Stenning, "Rotating stall and surge," ASME Journal of Fluids Engineering, vol. 102, no. 1, pp. 14-20, 1980.

[26] M. Ogata and A. Ichiro, "An experimental study of rotating stall in a radial vaned diffuser," in Proceedings of the International Symposium on Unsteady Aerodynamics and Aeroelasticity of Turbomachines, pp. 625-641, 1995.

[27] Y. Yoshida, Y. Murakami, T. Tsurusaki, and Y. Tsujimoto, "Rotating stalls in centrifugal impeller/vaned diffuser systems," in Proceedings of the 1st ASME/JSME Joint Fluids Engineering Conference, vol. FED-107, pp. 125-130, Portland, Ore, USA. 


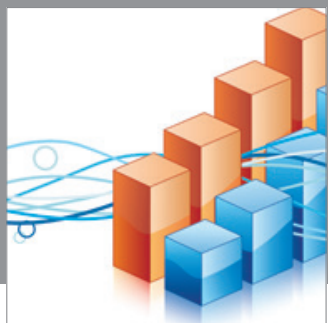

Advances in

Operations Research

mansans

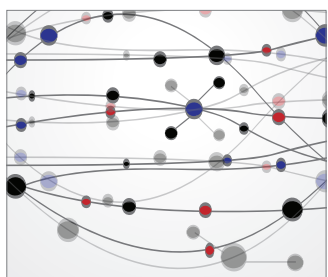

The Scientific World Journal
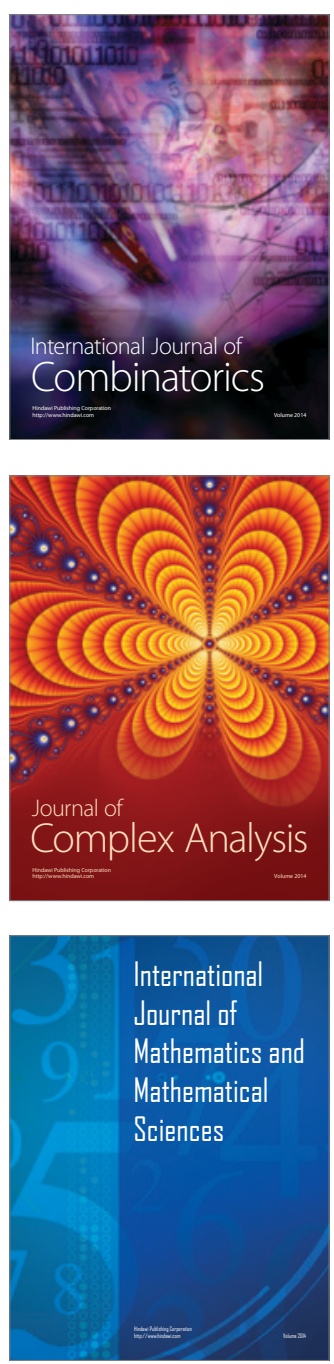
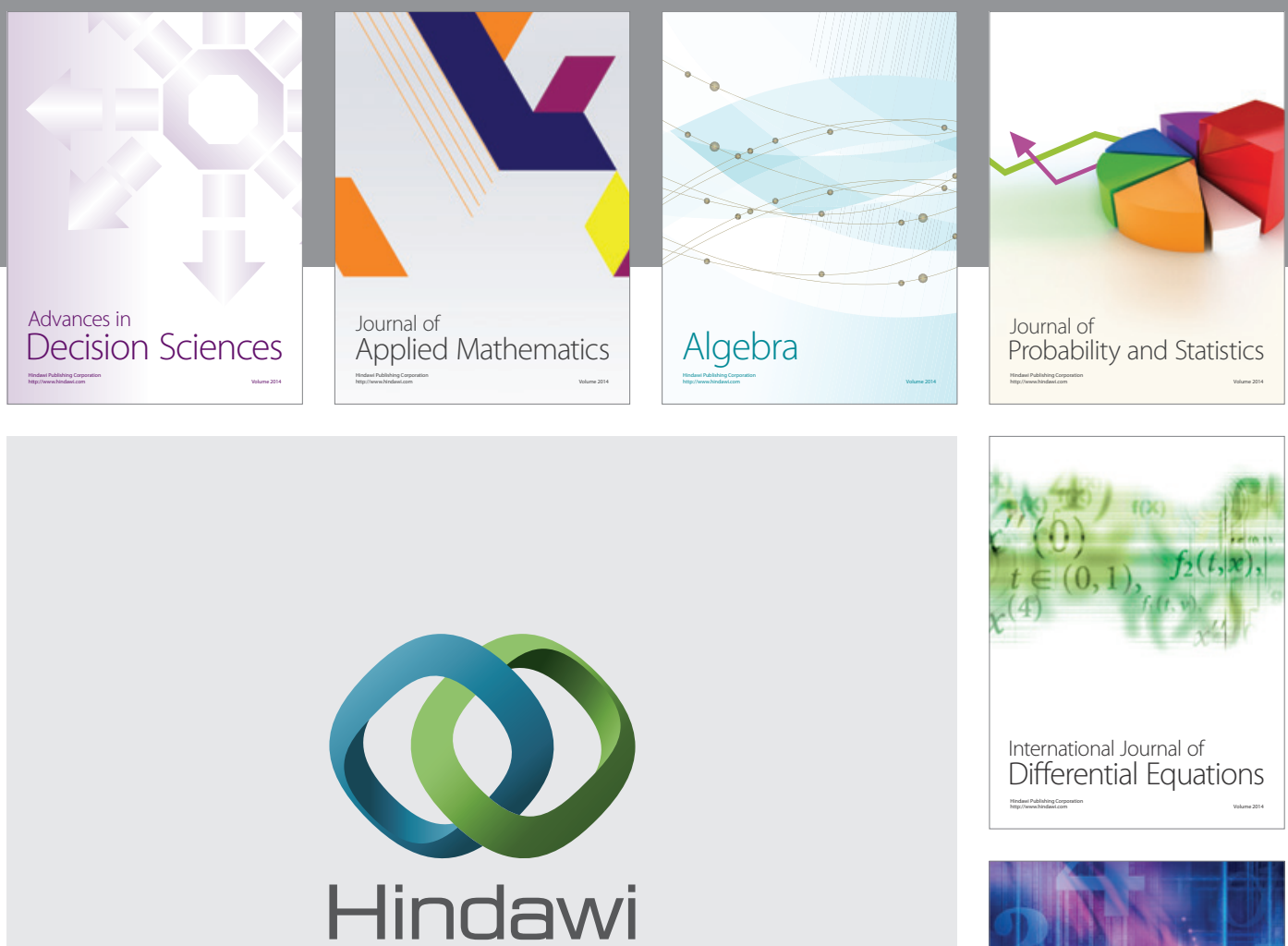

Submit your manuscripts at http://www.hindawi.com
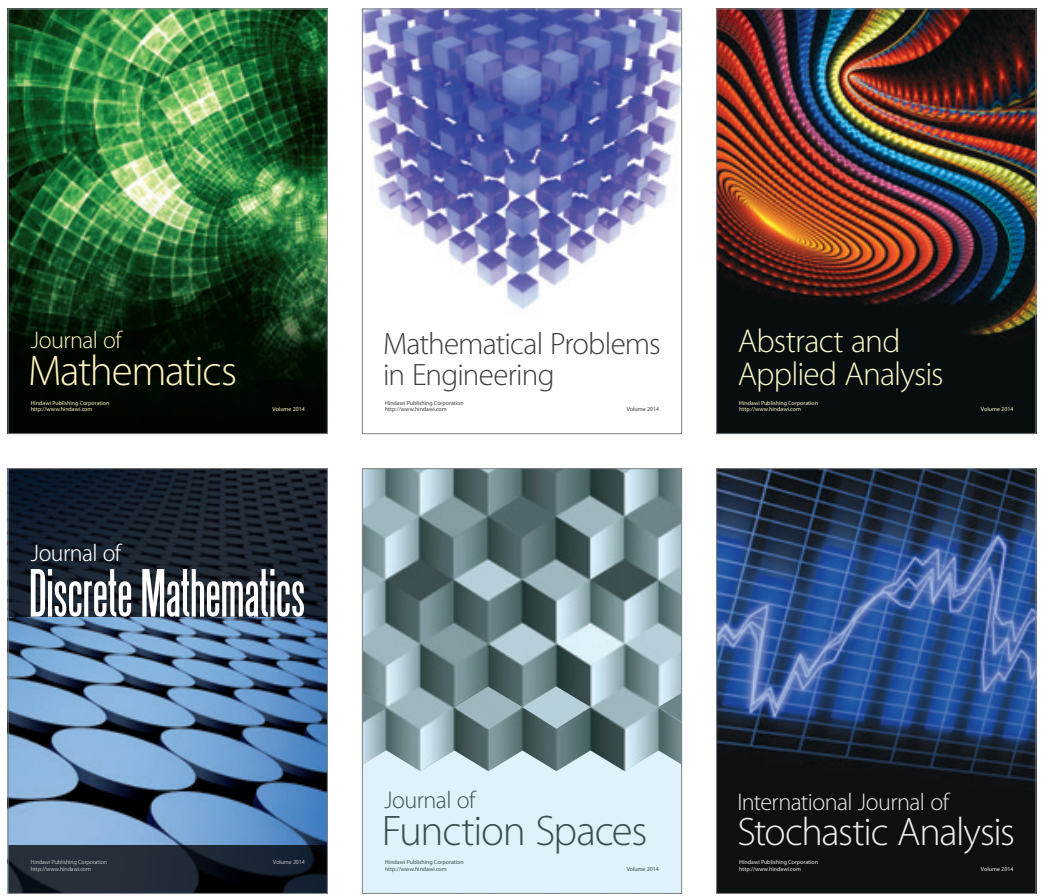

Journal of

Function Spaces

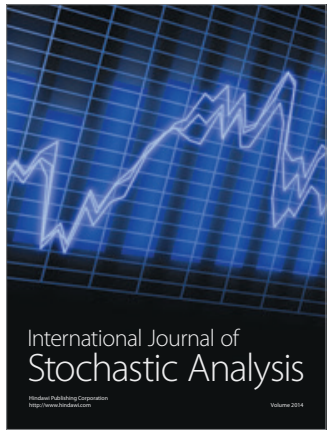

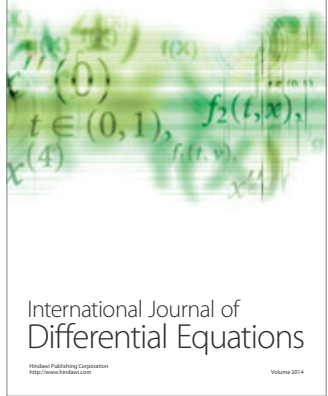
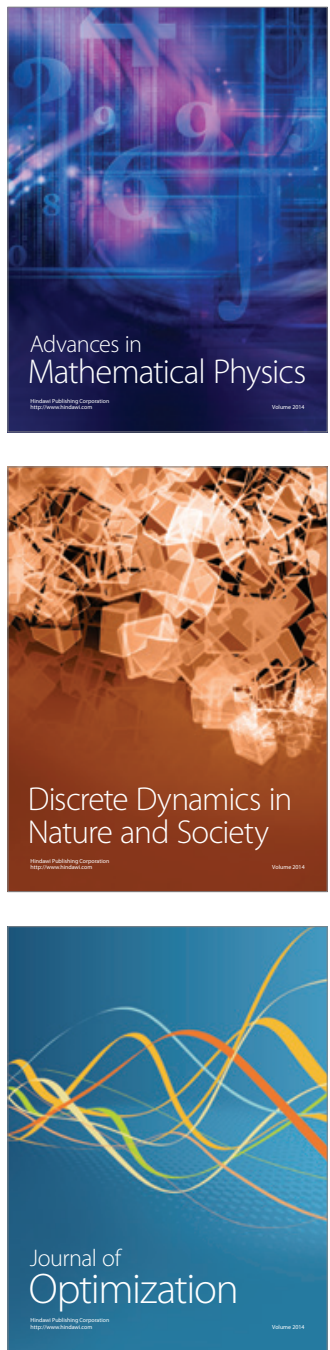